\title{
Behavior of Embankments Constructed on Soft Soil Deposits Reinforced with Rigid Inclusions
}

\author{
Mohamed M. S. El-Gendy, Ayman L. Fayed, Yasser M. El-Mossallamy
}

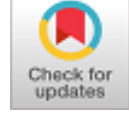

\begin{abstract}
Large settlement associated with the construction of embankments on soft soil deposits is a challenging geotechnical problem that needs a special treatment. Reinforcing the embankments utilizing geosynthetics is an effective technique used to reduce the differential settlement, while the total settlement is unchanged. A more efficient technique is utilizing a combination between soft soil reinforcement using piles or rigid inclusions, thus increasing the equivalent stiffness of the entire soft soil stratum, and a load transfer layer reinforced by one or more layers of geosynthetics on top of the inclusions' head, in order to improve the load distribution process between the rigid elements.

In this paper, the behavior of soft soil deposits reinforced with rigid inclusions is studied using three-dimensional finite element analysis, utilizing the "PLAXIS 3D 2020" software. Verification of the adopted modeling procedures is performed by the back analysis of a well-documented case study of a physical laboratory scaled model. Results of the numerical model showed a good agreement with the laboratory measurements in terms of both the settlement and load distribution aspects.
\end{abstract}

Furthermore, results of both the developed numerical model and selected performed numerical analyses, from the literature, for the same case study, were compared showing better efficiency of the developed model compared to others and more consistency with the real behavior of the laboratory model.

The verified model confirmed the efficiency of increasing the friction angle of the embankment on the load transfer mechanism between the rigid inclusions, and hence decreasing the resultant settlement.

Keywords: Soft Soil, Rigid inclusions, Piled embankment, Numerical model.

\section{INTRODUCTION}

Soft soil deposits are generally characterized by low bearing capacity and high compressibility; thus, improvement of such deposits is mandatory prior to construction. Different improvement techniques are usually adopted to improve soft soils such as stone columns, vertical drains accompanied by preloading, rigid inclusions such as controlled modulus columns (CMCs), and many other methods. Rigid inclusions are successfully used to control the

Revised Manuscript Received on April 25, 2020.

* Correspondence Author

Mohamed S. El-Gendy*, Structural Department, Faculty of Engineering, Ain Shams University, Cairo, Egypt. Email: m_salah@eng.asu.edu.eg

Ayman L. Fayed, Structural Department, Faculty of Engineering, Ain Shams University, Cairo, Egypt. Email: ayman.fayed@eng.asu.edu.eg

Yasser M. El Mossallamy, Structural Department, Faculty of Engineering, Ain Shams University, Cairo, Egypt. Email: yasserelmossallamy@gmail.com

(c) The Authors. Published by Blue Eyes Intelligence Engineering and Sciences Publication (BEIESP). This is an open access article under the CC BY-NC-ND license (http://creativecommons.org/licenses/by-nc-nd/4.0/) settlement and increase the bearing capacity of the foundations constructed in weak soil formations.

Physical laboratory models are commonly used to investigate the effectiveness of the ground improvement approach using rigid inclusions. Test results demonstrate that the composite foundation with rigid inclusions can reduce the settlement of the embankments significantly [1]. A full-scale field vertical load test was conducted on a controlled modulus column to investigate the short-term effects of installation on the surrounding soil [2]. Controlled Modulus Columns (CMCs) were studied to investigate their effect on the stability of slopes [3]. Elasto-Plastic finite element analysis was conducted to simulate the embankment soil foundation system, including different subsurface layers' properties and CMCs, where the developed model was verified using field data and showed reasonable agreement with the observed performance of the embankment in terms of the vertical displacements [4]. Furthermore, a series of laboratory tests of embankments resting on rigid inclusions was conducted, consisting of 12 trials [5]. The study was divided into two parts. The first part of the study aimed to clarify the load distribution on the piles, deformations in the geosynthetic reinforcement (GR) and subsoil, and the strains caused by the vertical load. The tests are similar to those reported by [6] and [7], which form the basis of the German standards [8]. Numerical models were performed based on the physical model reported by [5], using PLAXIS software to simulate the scaled model test, as illustrated by [9], and other models reported by [10] and [11]. In this paper, the finite element code, PLAXIS 3D 2020, is employed to simulate the laboratory model of [9]. Verification of the FEM is performed to confirm the validity of utilizing the finite element method in numerically simulating the behavior of embankments on soft soils deposits improved using rigid inclusions, and to study the main factors affecting the efficiency of this ground improvement technique.

\section{THE LABORATORY SCALED TEST (K2)}

[9] adopted a model similar to the model introduced by [6]. The model consists of a steel box, subsoil, embankment, piles, geosynthetics, and loads, as shown in Fig. 1.

Four piles are fixed on the box base, and then a foam cushion, simulating the soft soil, is placed between the piles. The box is then filled with water to simulate the groundwater table. A sand layer laid above the foam cushion and piles, then the steel frame with the attached GR layer on it is placed on the top of the sand layer. Settlement transducers and strain gauges (as possible) are fixed to the GR rib and making sure that the strain gauges are set to zero, then the embankment fill is applied with a water cushion on the top of the embankment. Finally, the steel box is closed with its cover.

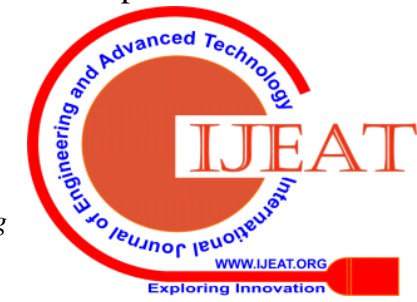


Table-I: Characteristics of the laboratory tests [9]

\begin{tabular}{|c|c|c|c|c|}
\hline Test no. Test code & $\begin{array}{c}\text { GR } \\
\text { description }\end{array}$ & GR material & $\begin{array}{c}\text { GR stiffness J 2\% } \\
\text { (direct. 1/direct. 2) } \\
\text { kN/m }\end{array}$ \\
\hline 1 & N1 & 2 laid grids biaxial & PET & 2090 \\
\hline 2 & N2 & 1 laid grid biaxial & PET & 1045 \\
\hline 3 & T1 & 1 woven geotextile & PP & 670 \\
\hline 4 & K1 & 1 woven grid biaxial & PVA & $2399 / 2904$ \\
\hline 5 & T2 & 1 woven geotextile & PP & $970 / 1810$ \\
\hline 6 & K2 & 2 woven grids & PVA & 2269 \\
\hline 7 & T3 & 1 woven geotextile & PP & $970 / 1810$ \\
\hline 8 & S1 & 2 extruded grids & PP & 757 \\
\hline 9 & T4 & 1 knitted grid biaxial & PET & $1715 / 1742$ \\
\hline 10 & K3 & 2 woven grids uniaxial & PVA & 2269 \\
\hline 11 & S2 & 2 extruded grids & PP & 757 \\
\hline 12 & N3 & 2 laid grids biaxial & PET & 2090 \\
\hline
\end{tabular}

The detailed construction stages are illustrated in Fig. 2. A series of twelve laboratory model tests were performed on piled embankments by [9], as illustrated in Table-I, to examine the validity of the existing EBGEO (2010) analytical model, in terms of the load distribution, deformations and strains, and hence improving the accuracy of the theoretical model. Each of the performed laboratory models was denoted by a certain identity code, in which the model (K2) is the case that is considered and studied in this paper. As a result of the laboratory model test outcomes, the total applied load is divided into three parts. Load part (A) is defined as the portion taken directly by the rigid inclusion (CMCs), while load part (B) is the load transferred to the CMCs via the developed tension in the geosynthetic reinforcement (GR). The remaining part of the total load that is denoted by the load part $(\mathrm{C})$ is defined as the load division carried by the subsoil around the rigid inclusions (foam cushion). Each of the three parts was measured directly using transducers through the laboratory tests for the sake of comparison with the analytical model results.

For the laboratory test (K2), Fig. 3 presents the relation between the net applied load on the $\mathrm{X}$-axis and the load parts $\mathrm{A}$ and $\mathrm{B}$ on the $\mathrm{Y}$-axis [5]. During the top-loading stages, where the top loads are applied while drainage is prevented, the absolute value of the load parts A and B increases, while their percentage relative to the total net load decreases due to the built-up porewater pressure. In the drainage stage, the absolute value of the load parts A and B increases as a result of the improvement in the arching behavior of the fill soil layer due to the dissipation of the built-up porewater pressure. Moreover, it can be noticed from Fig. 3 that the percentage of the load part $\mathrm{A}$, measured at the end of the drainage phases, decreases while the applied total net load increases. This demonstrates that the improvement in the arching effect is more significant in the lower loading values rather than the higher loading levels.

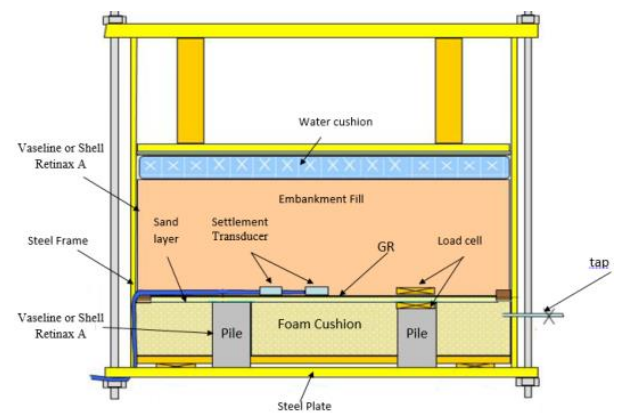

Fig. 1.Laboratory scaled-model components [5]

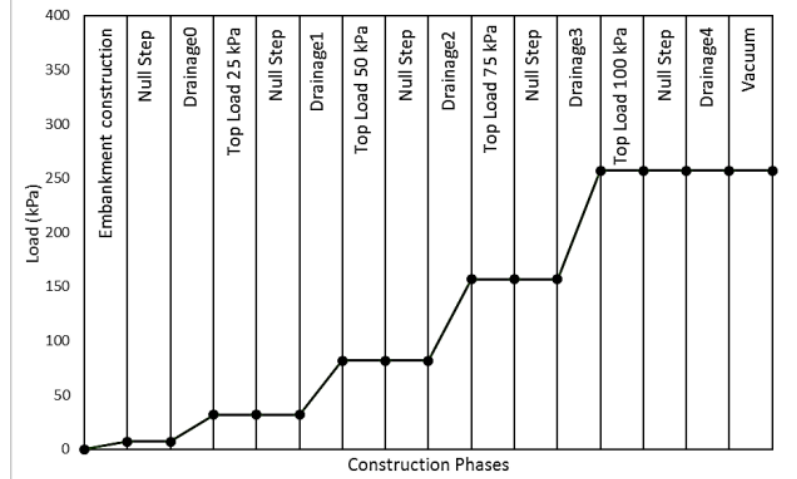

Fig. 2.Construction stages
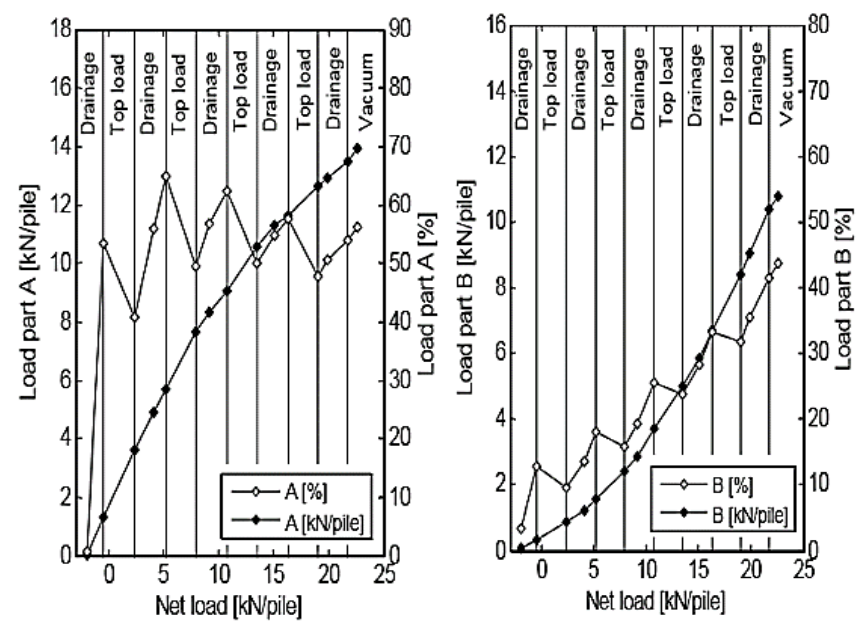

Fig. 3.Load parts A and B from the laboratory model [5]

\section{A. Measured vertical displacements}

The locations of the settlement transducers $\mathrm{z} 1, \mathrm{z} 2$ and $\mathrm{z} 3$ placed on the GR layer are shown in Fig. 4. The relation between the settlement values measured at these transducers, and the net loads applied to the embankment is shown in Fig. 5. As the net loads increase, the vertical displacement at each transducer increases.

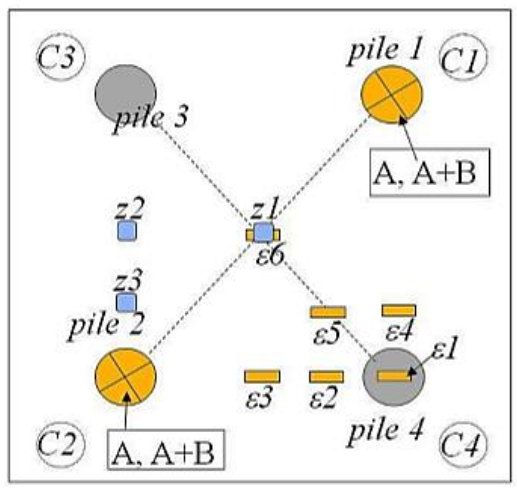

Fig. 4.Positions of the measuring equipment in the laboratory scaled-test [5]

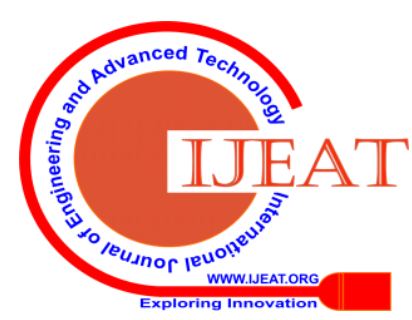




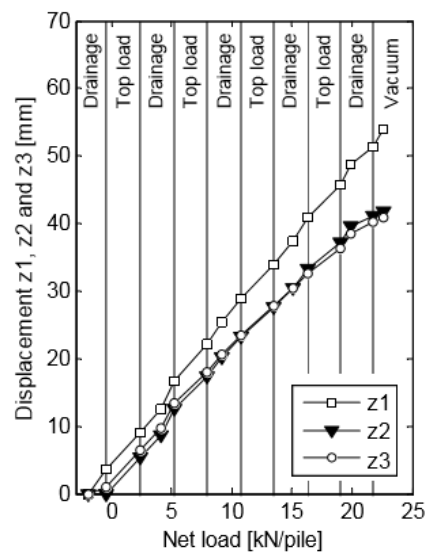

Fig. 5.Vertical displacements of the GR in the lab. test $\mathrm{K} 2$ [5]

\section{PREVIOUS NUMERICAL SIMULATION OF THE PHYSICAL MODEL}

The performed laboratory test and specifically the K2 scaled model test was subjected to extensive numerical modeling by different researchers as [10] and [11].

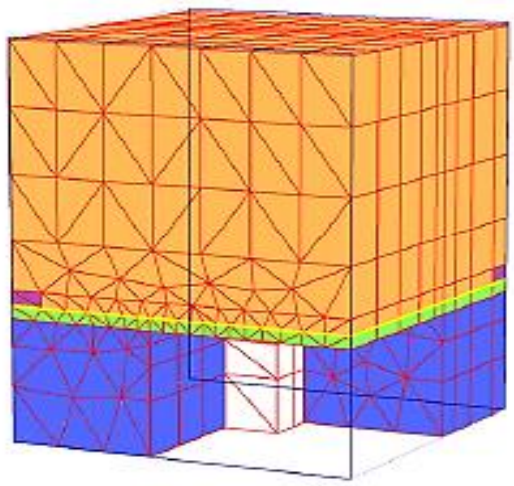

Fig. 6.Finite Element model of the lab. test K2 [10]

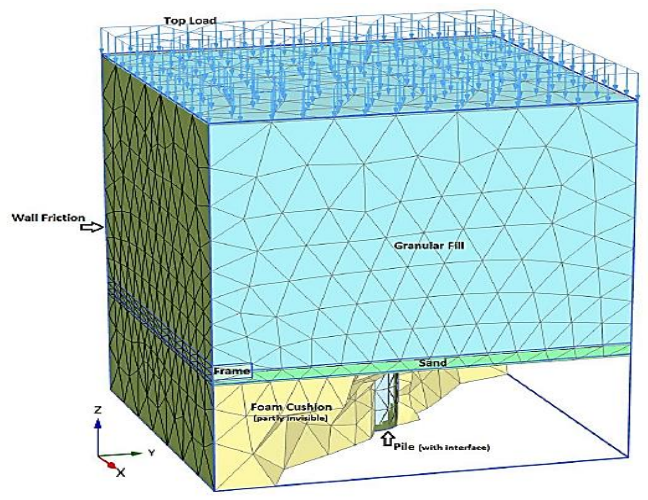

Fig. 7.Geometry of the developed 3D model [11]

[10] used PLAXIS 3D tunneling to simulate the physical laboratory model. Fig. 6 shows the mesh adopted in this simulation. Furthermore, [11] performed a numerical model by using the PLAXIS 3D software, where the used mesh is presented in Fig. 7.

\section{THREE-DIMENSIONAL NUMERICAL SIMULATION OF THE LABORATORY PHYSICAL MODEL K2}

\section{A. Model description}

Due to symmetry, only one-quarter of the problem is modelled, as a one pile surrounded by soft soil (foam

cushion), to minimize the analysis duration. The model extents are $0.55 \mathrm{~m}$ in both the $\mathrm{X}$ and $\mathrm{Y}$ directions. The horizontal movement is prevented at all the vertical boundaries. Furthermore, the drainage of the excess porewater pressure is not allowed at these boundaries through all stages. Both the horizontal and vertical movements of the lower horizontal boundary are not allowed, while the drainage of the excess porewater pressure is allowed only during the drainage phases.

\section{B. Constitutive models and materials parameters}

The numerical model adopted in the back analysis of the scaled model (K2) consists of several elements, including the pile, subsoil, sand, embankment fill, and the GR layer. The different parameters utilized in the model are based on the parameters stated by [10] and [11]. The developed mesh is shown in Fig. 8, furthermore, the parameters of the different elements adopted in the model are shown in Table-II and Table-III. The Linear Elastic (LE) constitutive model is used to simulate the behavior of the piles, foam cushion and the very dense sand layer above the piles' heads. The Hardening Soil constitutive model (HS) is adopted to model the sand soil above the foam cushion and the embankment fill.

Table-II: Geotechnical parameters and constitutive models adopted in the 3D F.E. model

\begin{tabular}{|c|c|c|c|c|c|c|}
\hline $\begin{array}{c}\text { Model } \\
\text { Property }\end{array}$ & Units & $\begin{array}{c}\text { Foam } \\
\text { Cushion }\end{array}$ & Pile & $\begin{array}{c}\text { Sand } \\
\text { Layer } \\
\text { Above } \\
\text { Foam } \\
\text { cushion }\end{array}$ & $\begin{array}{c}\text { Sand } \\
\text { Layer } \\
\text { Above } \\
\text { Pile }\end{array}$ & $\begin{array}{c}\text { Embankmen } \\
\text { t Fill }\end{array}$ \\
\hline $\begin{array}{c}\text { Constitutiv } \\
\text { e Model }\end{array}$ & - & LE & LE & HS & LE & HS \\
\hline Drainage & - & $\begin{array}{c}\text { undraine } \\
\text { d (A) }\end{array}$ & $\begin{array}{c}\text { Non-porou } \\
\text { s }\end{array}$ & Drained & Drained & Drained \\
\hline Yunsaturated & $\begin{array}{c}\mathrm{kN} / \mathrm{m} \\
3\end{array}$ & 10.15 & 13.64 & 18.67 & 18.67 & 16.59 \\
\hline $\mathrm{X}_{\text {saturated }}$ & $\begin{array}{c}\mathrm{kN} / \mathrm{m} \\
3\end{array}$ & 10.15 & - & 18.67 & 18.67 & 16.59 \\
\hline $\mathrm{E}_{50}{ }^{\text {Ref }}$ & $\begin{array}{c}\mathrm{kN} / \mathrm{m} \\
2\end{array}$ & 5.0 & $2.943 \times 10^{6}$ & $\begin{array}{c}19.66 \times 10 \\
3\end{array}$ & $\begin{array}{c}400.0 \times 10 \\
3\end{array}$ & $58.870 \times 10^{3}$ \\
\hline $\mathrm{E}_{\text {Oed }}^{\mathrm{Ref}}$ & $\begin{array}{c}\mathrm{kN} / \mathrm{m} \\
2\end{array}$ & 一 & - & $\begin{array}{c}19.66 \times 10 \\
3\end{array}$ & - & $58.870 \times 10^{3}$ \\
\hline $\mathrm{E}_{\mathrm{UR}}{ }^{\mathrm{Ref}}$ & $\begin{array}{c}\mathrm{kN} / \mathrm{m} \\
2\end{array}$ & - & - & $\begin{array}{c}58.98 \times 10 \\
3\end{array}$ & - & $176.60 \times 10^{3}$ \\
\hline $\mathrm{m}$ & - & - & - & 0.5 & - & 0.74 \\
\hline $\mathrm{C}$ & $\begin{array}{c}\mathrm{kN} / \mathrm{m} \\
2\end{array}$ & - & - & 1.0 & - & 1.0 \\
\hline$\varphi$ & o & - & - & 30.0 & - & 43.0 \\
\hline$\psi$ & o & - & - & 0.0 & - & 0.0 \\
\hline$v_{\mathrm{ur}}^{\prime}$ & - & 0.33 & 0.0 & 0.2 & 0.0 & 0.2 \\
\hline $\mathrm{P}_{\text {ref }}$ & $\begin{array}{c}\mathrm{kN} / \mathrm{m} \\
2\end{array}$ & - & - & 100 & - & 100 \\
\hline $\mathrm{K}_{0}{ }^{\mathrm{nc}}$ & - & - & - & 0.50 & - & 0.318 \\
\hline $\mathrm{R}_{\text {inter }}$ & - & 1.0 & 1.0 & 0.60 & 1.0 & 0.8 \\
\hline
\end{tabular}


Table-II: Geosynthetic Reinforcement properties \begin{tabular}{|l|l|l|}
\hline Geo-synthetic Reinforcement properties & Units & PVA woven Grids \\
\hline
\end{tabular}

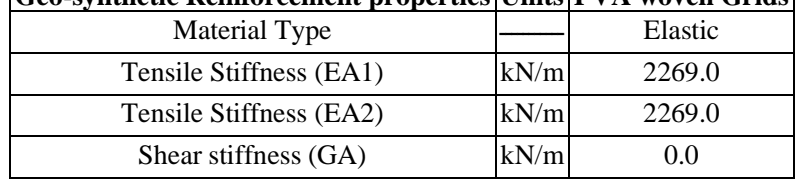

\section{COMPARISON BETWEEN THE RESULTS OF THE DEVELOPED NUMERICAL MODEL, LABORATORY SCALED TEST (K2) AND PREVIOUS PUBLISHED NUMERICAL MODELS}

\section{A. Load Distribution}

The load distribution results of the developed numerical model in this study are compared to the previous numerical models published by [10] and [11], as shown from Figures 9 to 12. The results yielding from the numerical model are divided into load parts (A, B and C) as well as the summation of both load parts $\mathrm{A}+\mathrm{B}$.

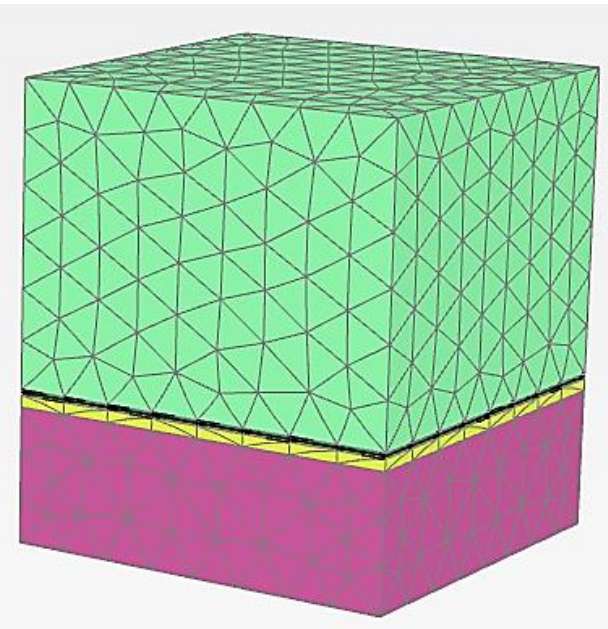

Fig. 8.Developed F.E. mesh for the K2 model

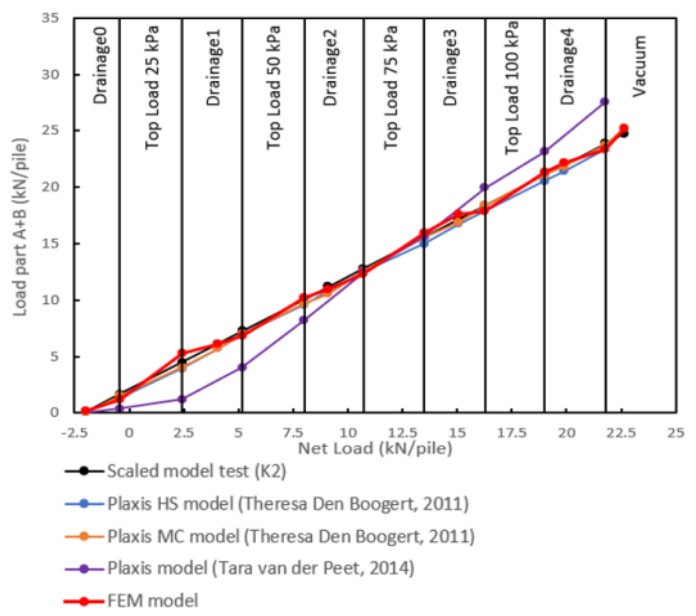

Fig. 9.Propagation of Load parts $(A+B)$ of the developed and investigated published numerical models

Fig. 9 shows the results of the summation of the load parts $\mathrm{A}$ and $\mathrm{B}$, that is transferred to the pile via both the arching effect and tension in the GR. The figure shows a good agreement between the values estimated by the developed numerical model, the scaled model (K2), and the numerical model presented by [10], while the values estimated by the numerical model introduced by [11] are inconsistent with other models.

Furthermore, all numerical models show similar behavior to the actual behavior recorded in the laboratory model when considering the load part C, as shown in Fig. 10.

Fig. 11 shows that both the developed and the previously published numerical models are able to reasonably predict the value of the load part $\mathrm{A}$, in comparison with the measured results of the scaled model (K2), only at the early stages of the test, till the application of the $50 \mathrm{kPa}$ top load. After that, the numerical models tend to slightly overestimate the value of the load. This applies to all the investigated models except the one presented by [11] that shows a large difference between the measured and predicted values during all stages.

Similarly, the load part B yielding from [10] shows a good agreement with the scaled model measurements and the back-analysis values till the application of the $50 \mathrm{kPa}$ top load, after which divergence occurs between the curves. Moreover, the values from [11] numerical model are generally less than both the back analysis and the laboratory measurements, as shown in Fig. 12.

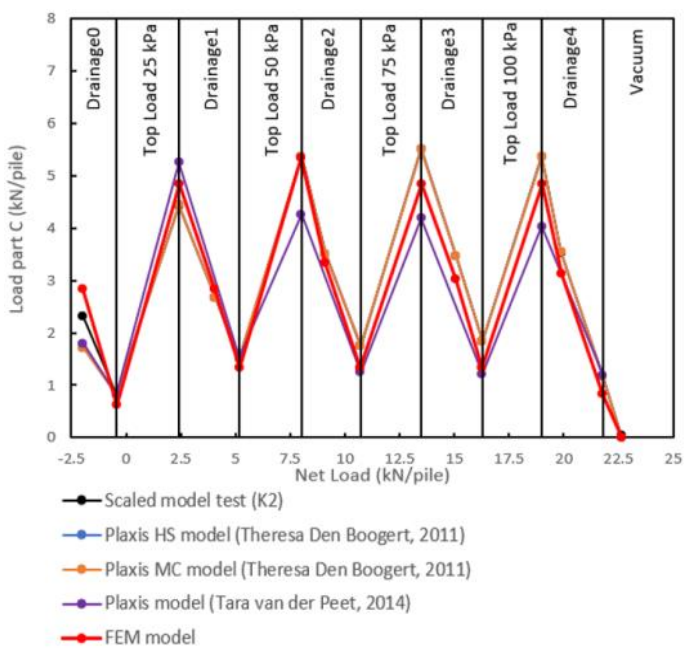

Fig. 10. Propagation of Load part $C$ of the developed and investigated published numerical models

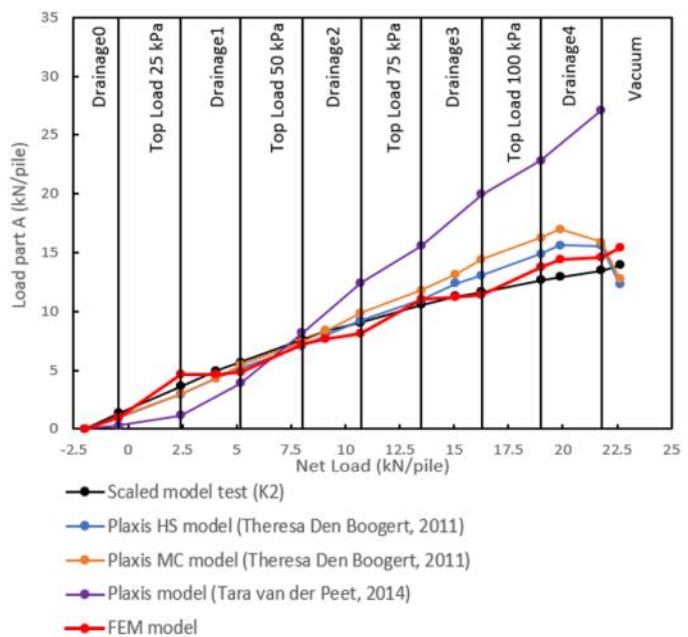

Fig. 11. Propagation of Load part A of the developed and investigated published numerical models

Published By:

Blue Eyes Intelligence Engineering \& Sciences Publication

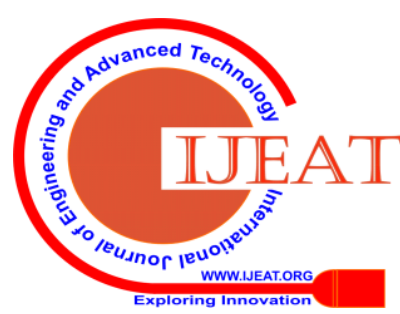




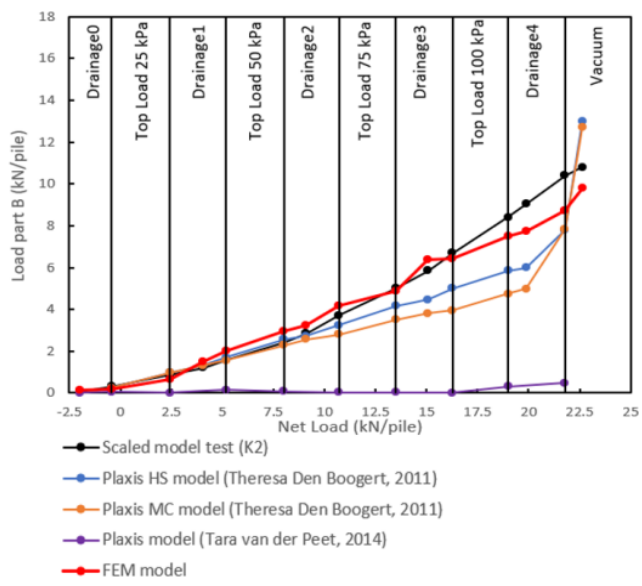

Fig. 12. Propagation of Load part B for various numerical models

\section{B. Vertical Displacement} laboratory tests using transducers at three different locations denoted as z1, z2 and z3, as shown in Fig. 4. Results of the numerical models, either the one developed through this study or the others published in the literature and investigated within the scope of this paper, are compared to the physical model's monitored displacements.

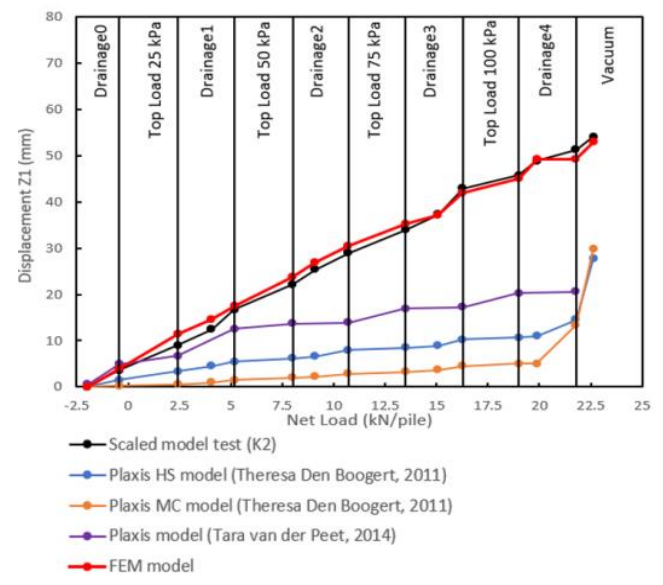

Fig. 13. Values of the vertical displacement at $\mathrm{z} 1$ for the developed and investigated published numerical models

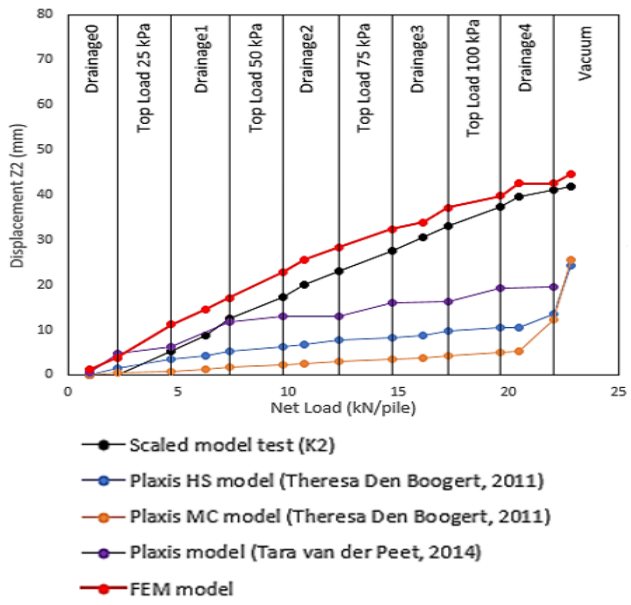

Fig. 14. Values of the vertical displacement at $\mathrm{z} 2$ for the developed and investigated published numerical models
The vertical displacement was monitored during the

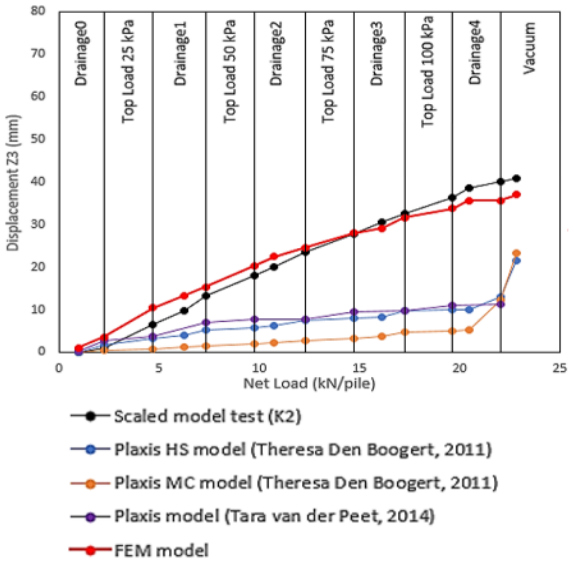

Fig. 15. Values of the vertical displacement at $\mathrm{z} 3$ for the developed and investigated published numerical models

Figures 13 to 15 demonstrate the comparison between the calculated and measured displacements. From these figures, it can be clearly noticed the good agreement between the results of the developed numerical model and the monitored values in the lab. The developed model can predict the vertical displacements at different locations with higher accuracy than the other investigated previously conducted and published numerical analyses.

\section{EFFECT OF THE EMBANKMENT'S ANGLE OF INTERANAL FRICTION ON THE ARCHING EFFECT AND LOADS ON THE RIGID INCLUSIONS}

The efficiency of utilizing rigid inclusions in improving the behavior of soft soil deposits depends on several parameters. The shear parameters of the embankment are considered the main factors that affect the mechanism of distributing the applied loads between both the rigid inclusions and the soft soil deposit, thus influencing the final achieved settlement.

The verified numerical model was used to investigate the effect of the internal friction angle value of the embankment soil on both the final settlement and the load distribution between the inclusions and the soft soil.

The results for settlement are shown in figures 16 to 18 .

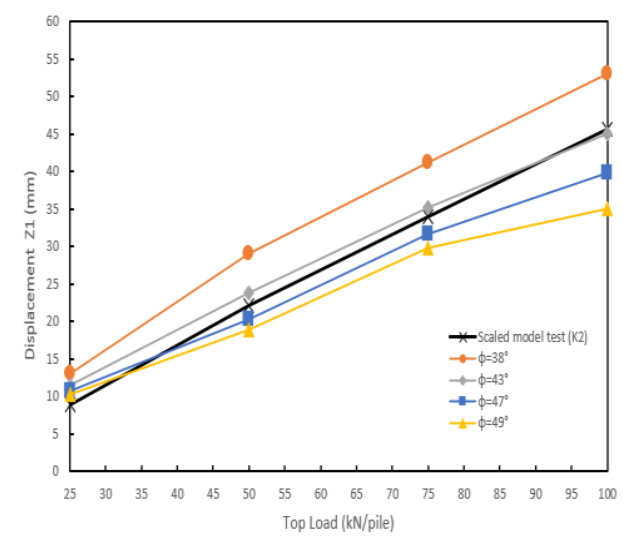

Fig. 16. Values of the vertical displacement at $\mathrm{z1}$ for various embankment's angle of internal friction 


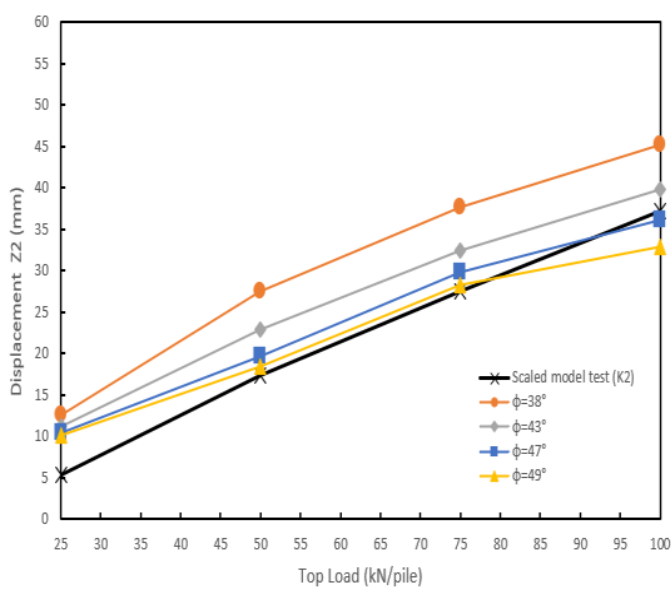

Fig. 17. Values of the vertical displacement at $\mathrm{z} 2$ for various embankment's angle of internal friction

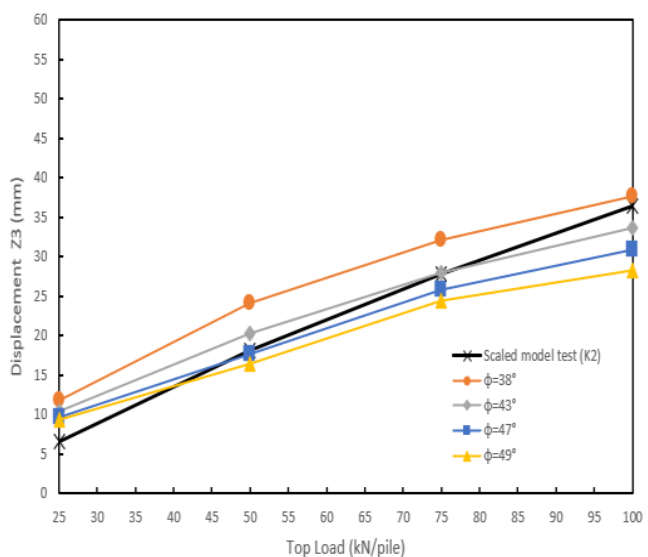

Fig. 18. Values of the vertical displacement at $\mathrm{z} 3$ for various embankment's angle of internal friction

A common behavior is recognized from these figures showing that the resulting estimated settlement at the different locations; z1, z2 and z3 respectively, is generally decreasing with the increasing of the internal friction angle of the embankment soil. This phenomenon can be attributed to the improvement in the arching action, and hence less loads are transferred to the soft soil, while a larger part is taken by the rigid piles.

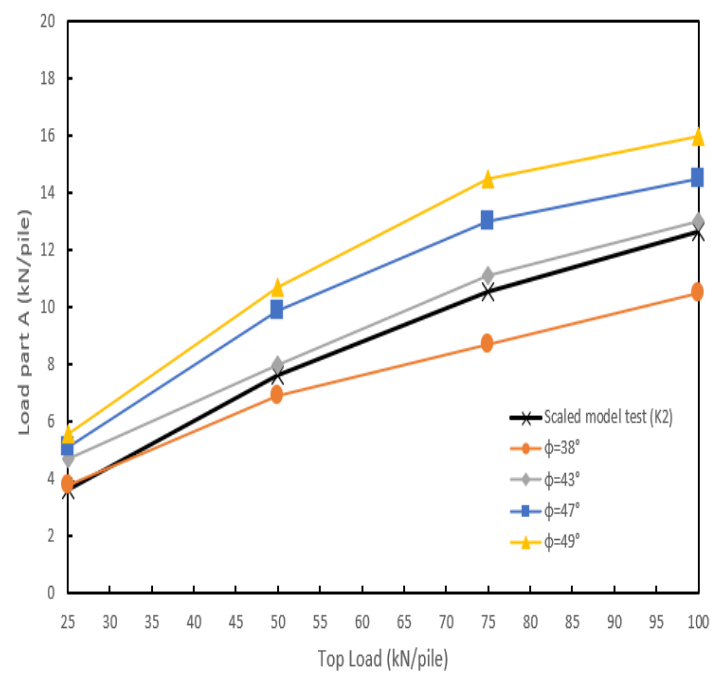

Fig. 19. Values of the load part $A$ for various embankment's angle of internal friction

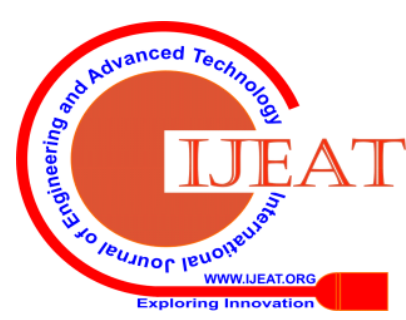


The main points of comparison and interest are the load distribution between the rigid inclusions and the associated vertical displacements. The performed analyses clearly showed the capability of the developed sophisticated numerical model to reasonably simulate the actual behavior of the laboratory test. The obtained results and comparison with the previously published numerical models, for the same case study, revealed the ability of the developed model to simulate the arching effect and hence estimate the way of load distribution between the rigid inclusions and the soft soil deposit. The obtained results also showed the significant preference of the developed finite element model, over other investigated published numerical studies, for accurately predicting the settlement values at different locations. Although, the previous numerical models presented by [10] display similar behavior to that recorded in the laboratory, at the early stages, in terms of the load distribution, but the estimated vertical displacement values were considerably lower than that recorded in the laboratory. Moreover, the model introduced by [11] shows an inconsistent behavior in terms of both the load distribution and vertical displacement.

The performed parametric study using the verified numerical model, showed clearly the improvement in the arching effect of the embankment as a result of the increase in its internal angle of friction, which led to decreasing the obtained vertical displacements accordingly.

\section{REFERENCES}

1. L. Miao, F. Wang, Y. Zhang, and C. Zhang, "Experimental study on controlled modulus column methods," Geotech. Spec. Publ., vol. 41025, no. 188, pp. 112-119, 2009, doi: 10.1061/41025(338)12.

2. M. T. Suleiman, L. Ni, C. Davis, H. Lin, and S. Xiao, "Installation Effects of Controlled Modulus Column Ground Improvement Piles on Surrounding Soil," J. Geotech. Geoenvironmental Eng., vol. 142, no. 1, pp. 1-10, 2016, doi: 10.1061/(ASCE)GT.1943-5606.0001384.

3. S. Briet, B. Manager, and C. Canada, "Construction of Highway Embankment Using Controlled Modulus Columns,” pp. 1-8, 2015.

4. Z. A. Alkaissi, "Numerical Analysis of Controlled Modulus Column Foundation System Supported,” vol. 15, no. 2, pp. 3691-3709, 2009.

5. Suzanne J.M. van Eekelen, piled embankment model. 2012.

6. D. Zaeske, Zur Wirkungsweise von unbewehrten und bewehrten mineralischen Tragschichten über pfahlartigen Gründungselementen. Fachgebiet u. Versuchsanst. Geotechnik, Univ. Gh Kassel, 2001.

7. C. Heitz, Bodengewölbe unter ruhender und nichtruhender Belastung bei Berücksichtigung von Bewehrungseinlagen aus Geogittern, vol. 19. kassel university press GmbH, 2006.

8. EBGEO, “die Berechnung von Erdkörpern mit Bewehrungen aus Geokunststoffen-EBGEO, Herausgegeben von der deutschen Gesellschaft für Geotechnik e," V.,(2. Auflage), Berlin Ernst Sohn, 2010.

9. S. J. M. Van Eekelen, A. Bezuijen, H. J. Lodder, and et A. F. van Tol, "Model Experiments on Piled Embankments. Part II," Geotext. Geomembranes, vol. 32, pp. 82-94, 2012.

10. T. J. M. den Boogert, "Piled Embankments with Geosynthetic Reinforcement," no. February, 2011.

11. T. Van Der Peet, "Arching in basal reinforced piled embankments," 2014.

\section{AUTHOR PROFILE}

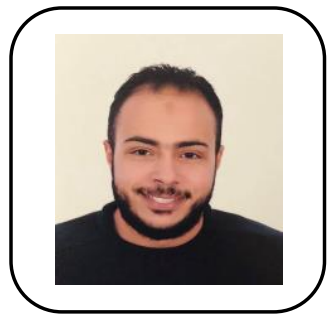

Eng. Mohamed Mohamed Salah El-Gendy is working as a demonstrator of geotechnical Engineering and foundations at Faculty of Engineering, Ain Shams University, Cairo, Egypt, since (2016). B.Sc. of Structural Engineering from Ain Shams University (2014). Member of the Egyptian Engineers Syndicate (since 2014). Eng. Mahmoud El-Gendy has over four years of experience in numerous structural and geotechnical engineering projects as a designer and consultant. Research interests cover soil mechanics, rock mechanics, soil improvement, soil stabilization, soft soil behavior, deep foundations, the behavior of problematic soils, and numerical modeling. Contact information: Geotechnical Engineering and Foundations Laboratory, Faculty of Engineering, Ain Shams University, 1 El Sarayat st., El Waili, Postal code 11535, Cairo, Egypt. Tel: +20-1007312859 E-mail: m_salah@eng.asu.edu.eg

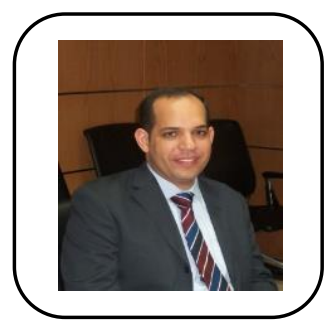

Dr. Ayman Fayed has over 25 years of experience as an educator, researcher, and consultant specializing in the areas of deep excavations, ground improvement, shallow and deep foundations, soil-structure interaction, and in-situ testing of soils. Dr. Fayed is a Professor (Assoc.) of geotechnical engineering at the faculty of engineering, Ain Shams University that is one of the top universities in the middle east and Africa.

Through his academic career, Dr. Fayed has authored or co-authored many publications in the geotechnical and foundation engineering field that were published in international journals and conferences. Dr. Fayed, as well, has supervised or co-supervised several M.Sc. and Ph.D. dissertations in geotechnical engineering. As an engineering consultant working at Dar Al-Hadassah consultants, which is one of the top engineering firms in the world, Dr. Fayed has participated in the design and management of many Mega-scale geotechnical projects in different regions of the world especially in the middle east and Africa.

Contact information: Geotechnical Engineering and Foundations Laboratory, Faculty of Engineering, Ain Shams University, 1 El Sarayat st., El Waili, Postal code 11535, Cairo, Egypt.

Tel: +20-1227372875

E-mail: ayman_fayed@eng.asu.edu.eg

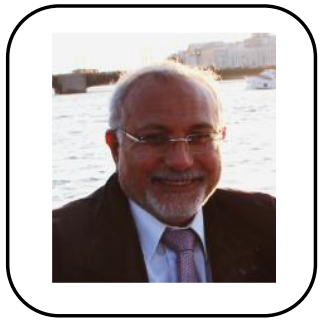

Prof. Yasser El-Mossallamy has been a researcher and consultant for 34 years. His work includes the application of numerical modeling and analyses in geotechnical projects. He has a wide experience by the design and construction of raft and piled raft foundations of high-rise buildings and bridge foundation. He was also involved in many projects dealing with special measures to increase stability of landslides, soil improvement, rock fall hazards and tunneling. Prof. El-Mossallamy has finished his PhD in Germany and has worked by ARCADIS Consult in Germany for about 13 years. Prof. El-Mossallamy joints till now Arcadis in many projects worldwide (e.g. 3rd Istanbul Airport). Prof. Yasser has a wide experience in different countries such as Germany, China, Turkey, Egypt, Saudi Arabia, Kuwait and UAE, Jordanian. Prof. El-Mossallamy has a wide experience with Mega projects dealing with foundation of high-rise buildings, bridges, tunnels, dams, highways, railways, airports and silos.

Prof. El-Mossallamy is also a professor at Ain Shams University, Cairo, Egypt. Prof. El-Mossallamy has more than 100 publications dealing with different geotechnical topics.

Contact information: Geotechnical Engineering and Foundations Laboratory, Faculty of Engineering, Ain Shams University, 1 El Sarayat st., El Waili, Postal code 11535, Cairo, Egypt.

Tel: +20-1006666502

E-mail: yasserelmossallamy@gmail.com
Published By:

Blue Eyes Intelligence Engineering \& Sciences Publication 2020 (C) Copyright: All rights reserved.

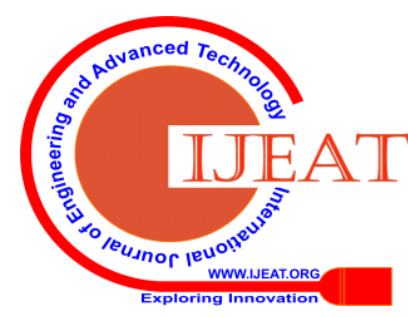

